\title{
Research on the Countermeasures of Relative Poverty Alleviation in Underdeveloped Areas
}

\author{
Yue Li \\ Southwest Minzu University, Chengdu, Sichuan, 610200, China \\ *Corresponding author. Email: liyue.0119@foxmail.com

\begin{abstract}
Based on simple analysis of current problems occurred after significant victory in poverty alleviation in the border area $\mathrm{X}$ of western Yunnan and in the process of efforts to continue the rural revitalization practice, this article illustrates the impact of these events on society as well as the causes, thus finding out some more problems to be improved in border governance. In the new stage, it will start useful exploration of the excellent local experience, desiring to improve the governance system of relative poverty in China, and find a good strategy to alleviate relative poverty.
\end{abstract}

Keywords: Underdeveloped area, Relative poverty, Governance.

\section{INTRODUCTION}

\subsection{Connotation of Relative Poverty}

Currently, the research is carried out by the academic circles mainly in terms of connotation, characteristics, identification standards, governance mechanisms and factors causing the relative poverty. In terms of its connotation, relative poverty is deemed as a kind of state that lags behind the general social level after meeting the basic living needs in the opinions of the most scholars. In the opinions of Guomin WANG, relative poverty includes two aspects: one is the poverty caused by increased low-income level due to the improvement of economic development level; The other is the poverty caused by the income gap among different regions, different classes and different members in the same class during the same period [1]. In terms of the causes of relative poverty, Xiaoyun LI et al. believe that the lack, insufficiency and unfair distribution of noncompetitive social public services are the important causes of relative poverty [2]. While other scholars hold the opinion that inadequate capability, system and social exclusion are the main factors that cause the relative poverty. In terms of characteristics of relative poverty, Chuanzhou ZHANG believes that relative poverty has the characteristics of continuity, subjectivity and risk, as well as has the characteristics of multi-dimension, large population base and expansibility compared with absolute poverty [3]. Other scholars also suggest to determine the standard of relative poverty based on people's basic needs. However, this needs to be further discussed and researched by academic circles. According to Lichao YANG and Robert Walker, income inequality is the direct cause of relative poverty in China, and the key aspect of measuring poverty is to understand the dynamic nature of poverty [4].

In conclusion, relative poverty is a developmental concept and refers to the state in which only living needs can be met based on the income level, but it fails to meet the needs of higher levels, which needs to be compared with the indicators stipulated by the state or local governments in current year.

\subsection{Connotation of Relative Poverty Governance and Significance on Research}

Poverty governance, as a systematic project, forms a part of the national governance system. Effective poverty governance cannot be achieved without optimization and upgrading of the national governance system [5]. Currently, China has developed a set of fairly complete system for absolute poverty governance, but in the new stage, the governance system framework that stabilizes the achievements of poverty alleviation, adapts to rural revitalization and focuses on solving relative poverty problem has not yet formed. Research on the framework of relative poverty governance can help make "China Power" continue to provide successful examples for world poverty alleviation 
efforts in the process of change of poverty pattern in China.

\section{MODEL FRAMEWORK OF RESEARCH ON RELATIVE POVERTY GOVERNANCE}

\subsection{Localized Improvement Based on SFIC Model}

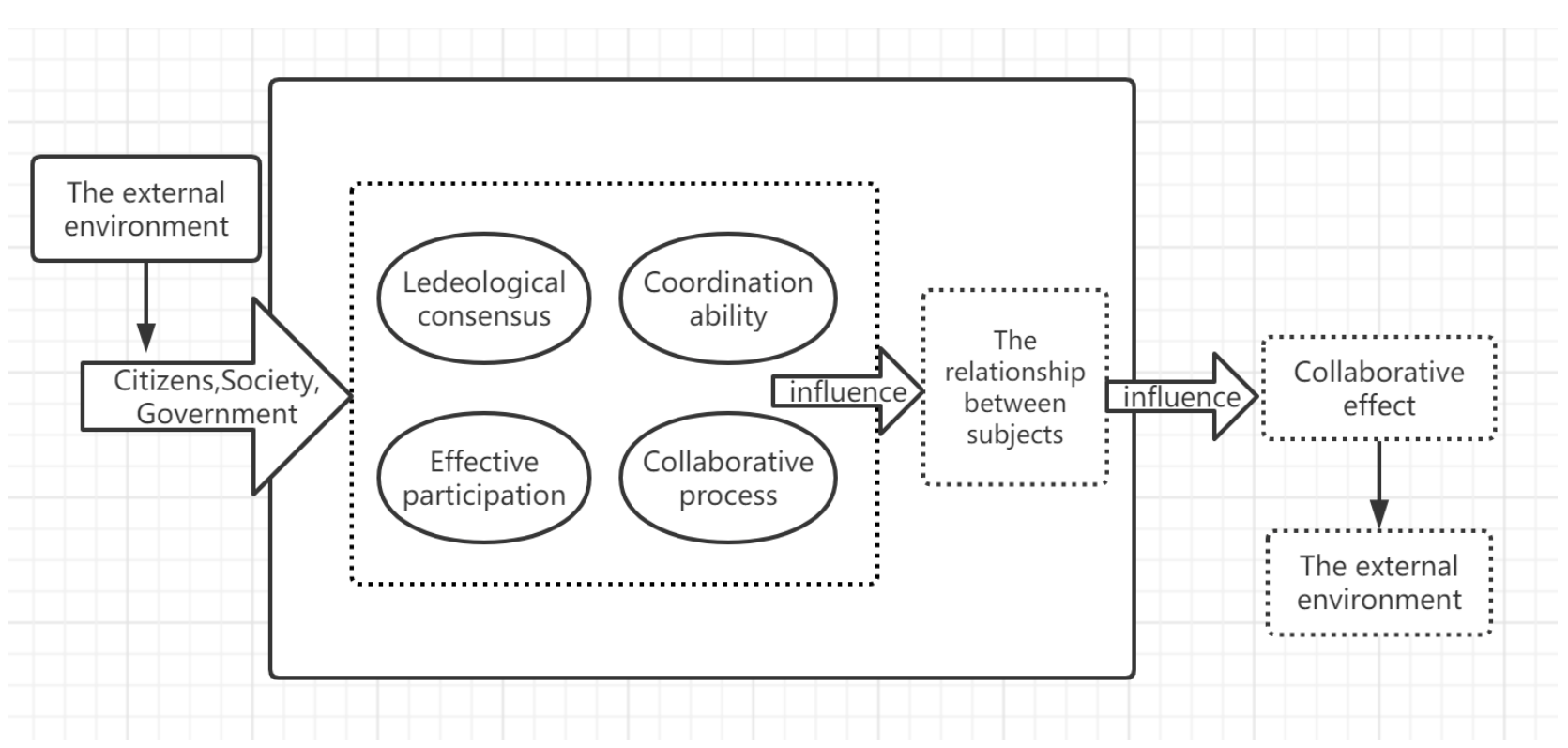

Figure 1 Research ideas of relative poverty

SFIC model has four parts: starting conditions, catalytic leadership, system design and collaborative process, and each of them contains some variables, which shall be used as references for subsequent research and verification after the scholars Ansell and Gash give some propositions [6]. The model in this article also obtains the research approaches on relative poverty governance in Figure 1 by referring to the research on SFIC model proposed by scholar Peijie TIAN [7].

Considering the current state of relative poverty caused by various internal and external factors, the government attaches importance to the alleviation of relative poverty and issues corresponding policies to support and form the external environment. With the government, citizens and other social organizations as the interconnected main subjects, and with citizens as the main force, it finally forms the base of relative poverty governance. The formation of the collaborative engine mainly depends on the participation ability, ideological consensus, participation enthusiasm and coordination mechanism among the three parties, and finally, it realizes the collaborative governance of Table 1. Regression coefficient $F$ test relative poverty by three parties. In this way, it will further affect the change of the external environment, thus leading to a new round of circulation.

\subsection{Quantitative Regression Analysis of the Model}

The table (Table 2) below shows the situation of the places investigated, and linear regression analysis is carried out by using ideological consensus, effective participation, coordination ability and collaborative process as independent variables and using collaborative effect as dependent variables. According to the above table, the model formula is:

Collaborative effect $=-0.511+0.241 *$ ideological consensus $+0.324 *$ effective participation $+0.241^{*}$ coordination ability $+0.353 *$ collaborative process, and the square value $\mathrm{R}$ of the model is 0.434 , which means that ideological consensus, effective participation, coordination ability and collaborative process can explain the reasons for $43.4 \%$ changes of collaborative effect.

During $F$ test of model, we find that the model passes $F$ test $(F=87.821, p=0.000<0.05)$, so it means that at least one index among ideological consensus, effective participation, coordination ability and collaborative process will affect the collaborative effect.

The regression coefficient of ideological It means that the starting conditions may have a consensus is $0.241(t=4.837, p=0.000<0.01)$ significant positive impact on the collaborative effect. 
The regression coefficient of effective participation is $0.324(t=6.343, p=0.000<0.01)$

The regression coefficient of coordination ability is $0.241(t=4.295, p=0.000<0.01)$

The regression coefficient of collaborative process is $0.353(t=6.736, p=0.000<0.01)$

Based on summary and analysis of Table 1: The ideological consensus, effective participation,

Table 2. Regression analysis results

It means that catalytic leadership may have a significant positive impact on the collaborative effect.

It means that the system design may have a significant positive impact on the collaborative effect.

It means that the collaborative process may have a significant positive impact on the collaborative effect.

coordination ability and collaborative process will have a significant positive impact on collaborative effect.

\begin{tabular}{|c|c|c|c|}
\hline \multicolumn{4}{|c|}{ Linear regression analysis results -simplified format } \\
\hline & Regression coefficient & $95 \% \mathrm{Cl}$ & VIF \\
\hline Constant & $\begin{array}{l}-0.511^{\star \star} \\
(-2.815)\end{array}$ & $-0.866 \sim-0.155$ & - \\
\hline Ideological consensus & $\begin{array}{l}0.241^{\star *} \\
-4.837\end{array}$ & $0.143 \sim 0.339$ & 1.237 \\
\hline Effective participation & $\begin{array}{l}0.324^{\star \star} \\
-6.343\end{array}$ & $0.224 \sim 0.424$ & 1.263 \\
\hline Coordination ability & $\begin{array}{l}0.241^{\star *} \\
-4.295\end{array}$ & $0.131 \sim 0.350$ & 1.344 \\
\hline Collaborative process & $\begin{array}{l}0.353^{\star \star} \\
-6.736\end{array}$ & $0.251 \sim 0.456$ & 1.483 \\
\hline Sample size & 464 & & \\
\hline $\mathrm{R}^{2}$ & 0.434 & & \\
\hline Adjustment $\mathrm{R}^{2}$ & 0.429 & & \\
\hline F value & $F(4,459)=87.821, p=0.000$ & & \\
\hline \multicolumn{4}{|c|}{ Dependent variable: Collaborative effect } \\
\hline \multicolumn{4}{|l|}{ D-W value: 0.148} \\
\hline${ }^{*} p<0.05 * * p<0.01$, th & is in brackets & & \\
\hline
\end{tabular}

\section{MAIN INNOVATION STRATEGIES OF GOVERNANCE MODEL IN UNDERDEVELOPED AREAS}

\subsection{Multi-subject Participation Under the Leadership of the Government}

Focus on the cultivation of residents' consciousness of self-confidence and self-improvement. Guide residents to develop legal awareness. The main reason why the residents lag behind is that they persist in the ideology of small-scale peasant economy, so it is required to strengthen the cultivation of residents' comprehensive qualities in all aspects, especially it shall form the consciousness of self-confidence and selfimprovement, which shall reach a consensus among residents. The government and society shall encourage citizens in underdeveloped areas to actively participate in social governance affairs.

Multi-subject participation under the leadership of the government. In essence, the collaborative governance means the process of coordinating social affairs to be jointly handled by the government and the society under the supervision and participation of residents, and it is the sum of individual management and various types of public organization management. In relatively underdeveloped areas, the government leadership factor has a great influence, but citizens' individual participation and social participation are not high. Only through the joint efforts of citizens, government and society can the problems of economic backwardness in underdeveloped areas be solved, and therefore, we can build a harmonious social environment.

\subsection{Attraction of Highly-competent Talents to Participate in Relative Poverty Governance}

Improve the talent guarantee mechanism. In the process of governance in relatively underdeveloped areas, a relatively complete talent introduction mechanism has been established, and the talent guarantee mechanism is of great significance to stabilize social governance effects. To better attract the talents, it must improve the construction of public services in 
local places, improve the level of public health and medical service, develop characteristic industries and carry out characteristic activities. Especially, it is required to improve the talent exchange mechanism and spread and popularize advanced knowledge and techniques.

Encourage talents in rural area to participate in the relative poverty governance. In the underdeveloped areas, people in rural area mostly account for a higher proportion, and if the talents in rural area participate in the governance of relative poverty, it can help effectively encourage the general residents to participate in collaborative governance. The talents in rural area are often well educated in ideological and ethical standards, and have a better understanding of the reasons for local economic backwardness, so it will be of great help to governance of relative poverty if talents in rural area are encouraged to participate in social governance, and it can even awaken the excellent spiritual strength of traditional culture by setting a new example.

\subsection{Rational Allocation of Social Resources in the Underdeveloped Areas}

Perfect the operation mechanism of social resources in the underdeveloped areas. In the process of social governance in the underdeveloped areas, especially in the process of resources allocation, it is of great significance to understand citizens' needs and help realize personal interests of citizens and common interests of the society. Therefore, the basic-level government in the underdeveloped areas shall further understand the needs of citizens, improve the distribution mechanism of social resources, especially it shall manage and distribute the funds in rural areas, which shall be done in an effective manner.

In the collaborative process, it shall expand the supervision channels of citizens. The citizens' supervision and effectiveness can provide a strong guarantee for reasonable allocation of social resources in the underdeveloped areas. Only by expanding the supervision channels of citizens can they express their demands reasonably and lawfully, and therefore, the needs of residents can be understood. To achieve this, the basic-level governments and communities shall enhance the transparency of the operation of public resources, thus allowing the residents to fully dispose of the resources.

\section{CONCLUSIONS}

The relative poverty exists absolutely, but due to the development of society as well as the efforts of the government, society and citizens, the governance situation gets better and better, and finally based on collaborative progress, it can ensure the effective circulation and distribution of social resources. The preconditions of its collaborative process can be improved to further optimize the collaborative effect to achieve the strategy of stimulating innovation and alleviating relative poverty finally.

\section{REFERENCES}

[1] Guomin WANG, Liqiong HE. Identification Standard and Collaborative Governance of Relative Poverty in China [J/OL]. Journal of Xinjiang Normal University (Philosophy \& Social Sciences Edition), 2021(03): 1-12

[2] Xiaoyun LI, Junjun YUAN and Lerong YU: On Rural Poverty Alleviation Strategies and Policies after 2020: Transformation from" Poverty Alleviation "to" Poverty Prevention ", Issues in Agricultural Economy, Issue 2 (2020)

[3] Chuanzhou ZHANG. Connotation, Measurement and Countermeasures of Relative Poverty [J]. Journal of Northwest University for Nationalities (Philosophy \& Social Sciences Version), 2020 (02): 112-119.

[4] Lichao YANG, Robert Walker. Poverty and Antipoverty after 2020: Review, Prospect and Suggestions [J]. Guizhou Social Sciences, 2020 (2)

[5] Yujiao JIA. Key Focuses of Relative Poverty Governance after 2020 [J]. People's Tribune 2021(14)

[6] Ansell, Chris, and Alison Gash. 2007. Collaborative governance in theory and practice. Journal of Public Administration Research and Theory 18: 543-571.

[7] Peijie TIAN. Collaborative governance: Theoretical Research Framework and Analysis Model [D]. Shanghai Jiao Tong University, 2013. 